\title{
Can age-related mitochondrial dysfunction affect volatile anesthetic potency?
}

\author{
Michiaki Yamakage
}

Received: 1 August 2014/Accepted: 11 August 2014/Published online: 24 August 2014

(C) Japanese Society of Anesthesiologists 2014

Anesthetic potency is conventionally evaluated using the concept of MAC (minimum alveolar concentration). In a recent balanced anesthesia technique, MAC-awake was assessed as a more important parameter in clinical settings. The former is defined as the volatile anesthetic concentration that produces immobilization in $50 \%$ of patients subjected to a noxious stimulus, and the latter is defined as the concentration that suppresses appropriate response to commands in $50 \%$ of patients; memory is usually lost at this concentration. It is well established that opioid administration reduces the MAC of volatile anesthetics and the plasma concentration $\left(C_{\mathrm{p}}\right)$ of propofol required to prevent movement in response to noxious stimuli [1, 2]; however, opioids have little effect on MAC-awake and the $C_{\mathrm{p}}$ of propofol required for suppression of response to commands [3, 4].

We anesthesiologists are well aware that MAC-awake would be more precise and predictable compared to other intravenous hypnotics such as propofol $[4,5]$. Thus, due to the ease of continuous monitoring of end-tidal concentrations of inhalational agents, it is easier to use volatile anesthetics as hypnotics than as intravenous agents.

Several factors are known to alter anesthetic requirements and thereby, MAC and MAC-awake. MAC and MAC-awake are both known to decrease with increasing age [6] (Fig. 1). Mapleson [7] performed a meta-analysis to estimate the effect of age on MAC, finding a decrease in MAC of approximately $6 \%$ per decade for various volatile anesthetics (excluding data for subjects $<1$ year old because such data can deviate from the age-related decrease in MAC with increasing age). MAC-awake also

M. Yamakage $(\bowtie)$

Department of Anesthesiology, Sapporo Medical University

School of Medicine, South 1, West 16, Chuo-ku, Sapporo,

Hokkaido 060-8543, Japan

e-mail: yamakage@sapmed.ac.jp decreases with increasing age in a manner parallel to the effect of age on MAC itself. Thus, the ratio of MAC-awake to MAC does not change with increasing age (MACawake/MAC $=0.34$ ). MAC in animals, and presumably in humans as well, is known to decrease linearly with decreasing body temperature by $4-5 \%$ per ${ }^{\circ} \mathrm{C}$ [8]. Other factors, including severe hypotension, pregnancy, and hypoxemia, can also lead to a decrease in MAC, whereas hyperthermia and hyperthyroidism lead to an increase [9]. Interestingly, Liem et al. [10] found that red-haired volunteers required significantly more desflurane than darkhaired women (MAC: 6.2 vs. $5.2 \%$, respectively). Genetic analysis revealed that 9 of 10 red-haired volunteers were either homozygous or compound heterozygotes for mutations of the melatonin-1 receptors. Another group also revealed that the MAC in mice with nonfunctional melanocortin-1 receptors slightly exceeded that in control mice [11]. These studies were the first reports suggesting that changes in genotypes could affect anesthetic potency.

In this issue, Roelofs et al. [12] investigated the changes in isoflurane potency in knockout mice for the Ndufs 4 subunit of complex I, which regulates mitochondrial function, and found increased isoflurane sensitivity and severe respiratory depression during anesthesia in the knockout mice compared to their wild-type and heterozygous littermates. Interestingly, the respiratory depression during anesthesia was strongly progressive with age. Quintana et al. [13] recently reported almost identical data, with higher anesthetic sensitivity in Ndufs 4 knockout mice than in wild-type mice. This effect in mitochondrial complex I-deficient mice cannot yet be extrapolated to children with complex I deficiency because a human study directly pointing to a specific hypersensitivity to volatile anesthetics in people with Ndufs 4 deficiency has not been conducted. Other investigators revealed a protective effect on 


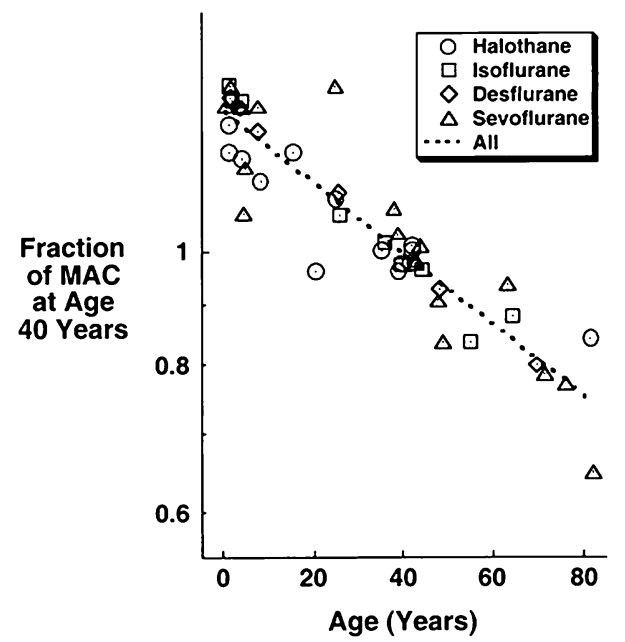

Fig. 1 Relationship between minimum alveolar concentration (MAC) and age, obtained from various studies, as cited in Ref. [6]. Each value of MAC at the patient age studied was divided by MAC at the age of 40 years. MAC decreased by $6.7 \%$ with each increasing decade of life

mitochondria responsible for cardioprotection against ischemia and reperfusion via anesthetic preconditioning [14].

Although the exact link between mitochondrial-complex I dysfunction and volatile anesthetic hypersensitivity remains difficult to explain, this study suggests that changes in mitochondrial function in the brain could affect volatile anesthetic potency [15]. It is possible that aging, which also affects volatile anesthetic sensitivity, may potentially have some effect on mitochondrial function in the brain [16]. With novel techniques, I am hoping to achieve marked improvement in controlling anesthetic potency in the near future.

\section{References}

1. McEwan AL, Smith C, Dyar O, et al. Isoflurane minimum alveolar concentration reduction by fentanyl. Anesthesiology. 1993;78:864-9.
2. Smith C, McEwan AL, Jhaveri R, et al. The interaction of fentanyl on the Cp50 of propofol for loss of consciousness and skin incision. Anesthesiology. 1994;81:820-8.

3. Katoh T, Suguro Y, Kimura T, Ikeda K. Morphine does not affect the awakening concentration of sevoflurane. Can J Anaesth 1993;40:825-8.

4. Iwakiri H, Nagata O, Matsukawa T, et al. Effect-site concentration of propofol for recovery of consciousness is virtually independent of fentanyl effect-site concentration. Anesth Analg. 2003;96:1651-5.

5. Chortkoff BS, Eger EI II, Crankshaw DP, et al. Concentrations of desflurane and propofol that suppress response to command in humans. Anesth Analg. 1995;81:737-43.

6. Eger EI II. Age, minimum alveolar anesthetic concentration, and minimum alveolar anesthetic concentration-awake. Anesth Analg. 2001;93:947-53.

7. Mapleson WW. Effect of age on MAC in humans: a meta-analysis. Br J Anaesth. 1996;76:179-85.

8. Satas S, Haaland K, Thoresen M, Steen PA. MAC for halothane and isoflurane during normothermia and hypothermia in the newborn piglet. Acta Anaesthesiol Scand. 1996;40:452-6.

9. Gelb AW, Leslie K, Stanski DR, Shafer SL. Monitoring the depth of anesthesia. In: Miller RD, editor. Miller's Anesthesia. Philadelphia: Churchill Livingstone; 2010. p. 1229-65.

10. Liem EB, Lin CM, Suleman MI, et al. Anesthetic requirement is increased in redheads. Anesthesiology. 2004;101:279-83.

11. Xing Y, Sonner JM, Eger EI II, et al. Mice with a melatonin 1 receptor mutation have a slightly greater minimum alveolar concentration than control mice. Anesthesiology. 2004;101: 544-6.

12. Roelofs S, Manjeri GR, Willems PH, et al. Isoflurane anesthetic hypersensitivity and progressive respiratory depression in a mouse model with isolated mitochondrial complex I deficiency. J Anesth 2014. [Epub ahead of print].

13. Quintana A, Morgan PG, Kruse SE, et al. Altered anesthetic sensitivity of mice lacking $N d u f s 4$, a subunit of mitochondrial complex I. PLoS One. 2012;7:e42904.

14. Hirata N, Shim YH, Pravdic D, et al. Isoflurane differentially modulates mitochondrial reactive oxygen species production via forward versus reverse electron transport flow: implications for preconditioning. Anesthesiology. 2011;115:531-40.

15. Falk MJ, Kayser E-B, Morgan PG, Sedensky MM. Mitochondrial complex I function modulates volatile anesthetic sensitvity in $C$. elegans. Curr Biol. 2006;16:1641-5.

16. Chistiakov DA, Sobenin IA, Revin VV, et al. Mitochondrial aging and age-related dysfunction of mitochondria. Biomed Res Int 2014. [Epub ahead of print]. 